\title{
M-CPOnes: Transition Metal Complexes with Cyclopropenone-Based Ligands for Light-Triggered Carbon Monoxide Release
}

\author{
Marc Lehr, ${ }^{[a]}$ Tjorge Neumann, ${ }^{[a]}$ Christian Näther ${ }^{[b]}$ and Anna J. McConnell ${ }^{*[a]}$ \\ a Otto Diels Institute of Organic Chemistry, Christian-Albrechts-Universität zu Kiel, Otto-Hahn-Platz 4, Kiel 24098, Germany. \\ ${ }^{b}$ Institute of Inorganic Chemistry, Christian-Albrechts-Universität zu Kiel, Max-Eyth-Straße 2, Kiel 24118, Germany.
}

A new class of CO-releasing molecules, M-CPOnes, was prepared combining cyclopropenone-based ligands for CO release with the modular scaffold of transition metal complexes. In proof-of-concept studies, M-CPOnes based on $\mathrm{Zn}$ ", Fe" and Co" are stable in the dark but undergo efficient light-triggered $\mathrm{CO}$ release with the cyclopropenone substituents and metal ions enabling tuning of the photophysical properties. Furthermore, the choice of metal allows the use of different spectroscopic methods to monitor photodecarbonylation from fluorescence spectroscopy to UV/vis spectroscopy and paramagnetic NMR spectroscopy. The modularity of M-CPOnes from the metal ion to the cyclopropenone substitution and potential for further functionalisation of the ligand makes M-CPOnes appealing for tailored functionality in applications

\section{Introduction}

Carbon monoxide has potential therapeutic applications, ${ }^{1}$ e.g. for treatment of inflammation and vascular dysfunction, ${ }^{2-5}$ given the role of carbon monoxide in the regulation of ion channels ${ }^{6,7}$ and signalling pathways. ${ }^{8,9}$ Since the safe handling and delivery of gaseous carbon monoxide is problematic, carbon monoxide releasing molecules (CORMs) ${ }^{3}$ have been developed for the controlled release of carbon monoxide in response to stimuli. These include metal carbonyl complexes ${ }^{10}$ (such as tricarbonyldichlororuthenium(II) dimer (CORM-2), ${ }^{11}$ (tricarbonylchloro(glycinato)ruthenium $\quad\left(\right.$ CORM-3) ${ }^{12}$ ), non-metallic/organic $\mathrm{CORMs}^{13}$ and carbon monoxide "prodrugs". ${ }^{14,15}$ For applications, the CORM should have good stability but triggerable and quantitative $\mathrm{CO}$ release as well as tunable photophysical properties and synthetic accessibility. ${ }^{16}$

Photo-CORMs ${ }^{17-20}$ take advantage of the spatial and temporal control of light to release carbon monoxide upon irradiation $^{16,21}$ and in some cases, the loss of carbon monoxide could be tracked by fluorescence. ${ }^{22-24}$ While cyclopropenones ${ }^{25,} 26$ undergo efficient photolysis ${ }^{27,} 28$ upon irradiation with light resulting in carbon monoxide release and alkyne formation, they have been largely overlooked as CORMs. ${ }^{16}$ Instead, cyclopropenones have found use across different fields from organic chemistry (as substrates in annulations, ${ }^{29-33}$ metal-catalysed ringopening reactions,,$^{34}$ cycloaddition reactions ${ }^{35,36}$ and allene syntheses $^{37,} 38$ as well as catalysts for nucleophilic substitutions $^{39,}{ }^{40}$ ) to material science ${ }^{18,} 41,42$ and biorthogonal chemistry. ${ }^{43-48}$

Cyclopropenones are appealing as prospective CORMs not only for their efficient photodecarbonylation but since they can be prepared via various synthetic methods (e.g. Friedel-Crafts reaction, ${ }^{49-53}[2+1]$ cycloaddition and hydrolysis, ${ }^{37,}{ }^{54-57}$ Favorskii rearrangement ${ }^{29}, \quad 39, \quad 58, \quad 59$ and substitution of cyclopropenone acetals $\left.{ }^{60-63}\right)$. In addition, they are stable in aqueous media and cellular environments ${ }^{45,47,64}$ and there is the potential to exploit multi-photon induced decarbonylation for carbon monoxide release at higher wavelengths $(800-950 \mathrm{~nm}) .65,66$

We envisaged the combination of cyclopropenones with transition metal complexes could lead to a new class of CO-releasing molecules, M-CPOnes (Scheme 1), as an alternative to metal carbonyl complexes; light could be exploited as a reagent-free trigger for $\mathrm{CO}$ release from the cyclopropenone while the transition metal complex could serve as a modular scaffold for not only introducing multiple cyclopropenone moieties but also tuning properties such as the stability, solubility and photodecarbonylation wavelength through the choice of metal and ligands.

We report cyclopropenone ligands based on a $2,2^{\prime}$-bipyridine coordination motif are now synthetically accessible via a cycloaddition and subsequent hydrolysis and in addition, their photophysical properties are tunable through the $\mathrm{R}$ substituent. The $\mathrm{M}-\mathrm{CPO}$ es resulting from complexation with $\mathrm{Zn}^{\prime \prime}, \mathrm{Fe}^{\mathrm{ll}}$ and $\mathrm{Co}^{\prime \prime}$ metal ions are stable in the dark but undergo efficient photodecarbonylation upon irradiation with $365 \mathrm{~nm}$ light (Scheme 1). Thus, we demonstrate the proof-of-concept of M-CPOnes as a new class of CO-releasing molecules.

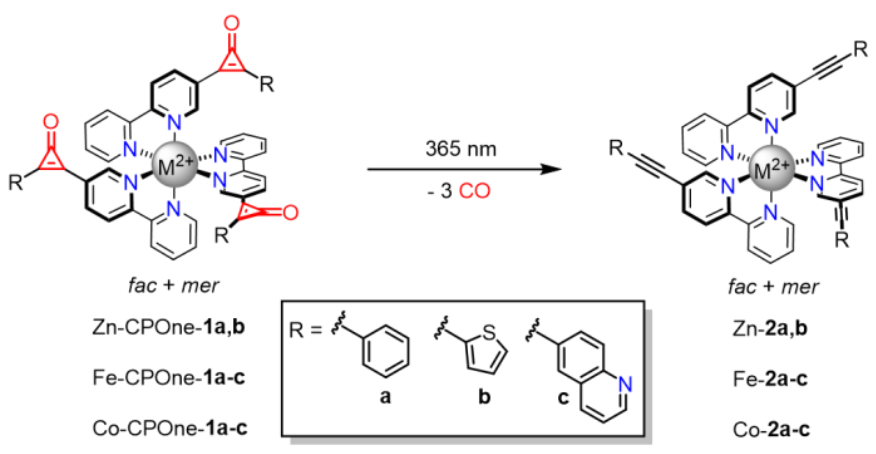

Scheme 1. Proof-of-concept of M-CPOnes: light triggered CO release from transition metal complexes with cyclopropenonebased ligands. The complexes form as a mixture of the fac and mer isomers but only the fac isomer is depicted for clarity. 


\section{Results and Discussion}

Given diphenylcyclopropenone is one of the simplest and most well-studied diaryl-substituted cyclopropenones, ${ }^{67-69}$ the initial target ligand was 1a (Scheme 2) where one of the phenyl groups was replaced with a simple 2,2'-bipyridine as the coordination motif for the development of this new class of CO-releasing molecules, M-CPOnes. Furthermore, ligands $\mathbf{1 b}$ and $\mathbf{1 c}$ would also be prepared where the second substituent was varied from a phenyl group to an electron rich thienyl and second $N$-heterocyclic substituent, respectively, to study the electronic effects of the aryl substituents on the stability and photophysical properties of the cyclopropenones and their corresponding M-CPOnes (Scheme 1).

While there are numerous examples of alkyl- and carbocyclic aryl-substituted cyclopropenones, ${ }^{25-29,39,41,45,}$ $47,58,59,62,63,65,66,70-72$ heterocyclic-based cyclopropenones are relatively rare ${ }^{73}$ and typically based on more electronrich 5-membered heterocycles. ${ }^{37,} 74,75$ Due to the incompatibility of Lewis acid reagents like $\mathrm{AlCl}_{3}$ with the 2,2'-bipyridine coordination motif in the commonly employed synthesis of cyclopropenones via a Friedel-Crafts reaction, ${ }^{76}$ we focused on an alternative synthetic strategy involving a [2+1] cycloaddition between a dihalocarbene ${ }^{77,78}$ and acetylene derivative followed by hydrolysis of the dihalocyclopropene (Scheme 2).

Even though the synthesis of difluorocyclopropenes via a cycloaddition is, in general, well established, ${ }^{78-80}$ there are a scarcity of examples of electron-deficient $\mathrm{N}$-heterocyclic difluorocyclopropenes. We expected the cycloaddition to be challenging given the more electron-deficient nature of the substrates and since Lewis bases such as pyridine have been proposed to coordinate to the : $\mathrm{CF}_{2}$ during the cycloaddition causing decomposition or difluoromethylation.77, 78, 81-84 We hypothesised the reduced basicity of 2,2'-bipyridine and 6-quinoline relative to pyridine might limit these side-reactions. Therefore, the feasibility of the $[2+1]$ cycloaddition reaction with 2,2'-bipyridine-based alkyne derivatives 2a-c (prepared according to Scheme S1) was investigated in NMR scale experiments.

Derivatives 2a-c, 1.5 eq. $\mathrm{TMSCF}_{2} \mathrm{Br}$ and $3 \mathrm{~mol} \%$ of the
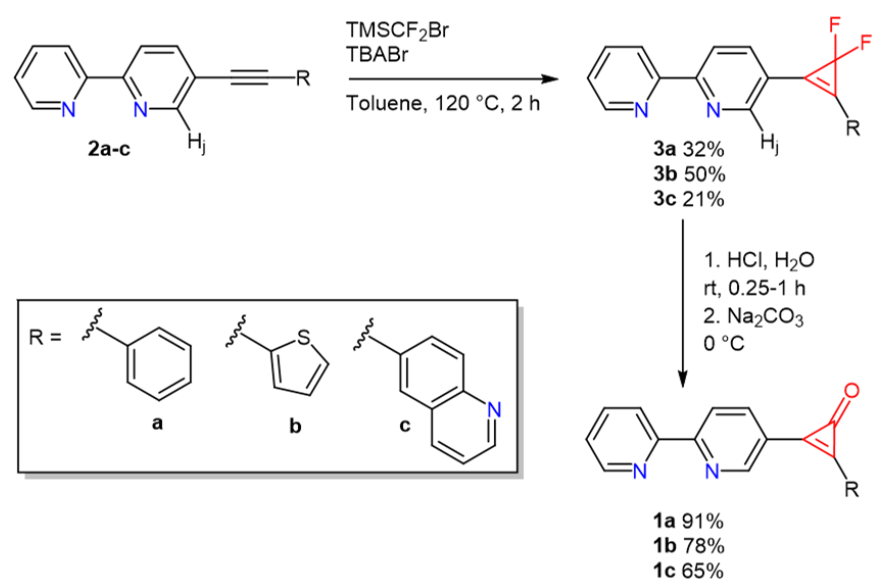

Scheme 2. Synthesis of $N$-heterocyclic cyclopropenones 1a-c via a [2+1] cycloaddition of : $\mathrm{CF}_{2}$ with alkyne derivatives $\mathbf{2 a - c}$ and subsequent hydrolysis of the corresponding difluorocyclopropenes 3a-c. initiator $\mathrm{TBABr}$ were heated in toluene- $d_{8}$ adapting literature procedures for related aryl-substituted difluorocyclopropenes. ${ }^{79}, 80$ The reaction mixture was monitored by ${ }^{1} \mathrm{H}$ and ${ }^{19} \mathrm{~F}$ NMR spectroscopy before and directly after a reaction time of $2 \mathrm{~h}$ (SI, Section 3 ). For all three derivatives, at least one new set of signals appeared in the ${ }^{1} \mathrm{H}$ NMR spectra (Figures S50, S52 and S54) and the ${ }^{19} \mathrm{~F}$ NMR spectra showed the consumption of $\mathrm{TMSCF}_{2} \mathrm{Br}$ as well as the presence of a new fluorine signal between -110 and -114 ppm (Figures S51, S53 and S55), which is consistent with the expected chemical shift of a difluorocyclopropene. ${ }^{79,80,84,85}$

The relative ratio of the unreacted alkyne and proposed difluorocyclopropene was determined by integrating the proton $\mathrm{H}_{\mathrm{j}}$ signal (Scheme 2) due to its characteristic chemical shift and separation from other signals (Figures S50, S52 and S54). Derivative 2b showed the highest product/starting material ratio (93:7, Table 1) and furthermore, the ${ }^{19} \mathrm{~F}$ NMR spectrum showed nearly complete consumption of $\mathrm{TMSCF}_{2} \mathrm{Br}$ (Figure S53). In contrast, the amount of the product significantly decreased for 2a and even more so for 2c with a second $N$-heterocyclic substituent (Table 1). Thus, better conversion to the difluorocyclopropene is observed in cycloadditions with substrates containing more electronrich $R$ substituents, as expected.

Table 1. Comparison of the conversions from in situ NMR experiments and isolated yields for the cycloaddition of substrates 2a-2c with : $\mathrm{CF}_{2}$.

\begin{tabular}{|c|c|c|}
\hline Substrate & 3:2 Ratio ${ }^{a}$ & $\begin{array}{l}\text { Isolated }^{\text {b }} \\
\text { Yield (\%) }\end{array}$ \\
\hline $2 a$ & $52: 48$ & 32 \\
\hline $2 b$ & $93: 7$ & 50 \\
\hline 2c & $18: 82$ & 21 \\
\hline
\end{tabular}

a Determined from NMR scale experiments $(0.1 \mathrm{mmol}$ of the respective alkyne substrate) and integration of the proton $\mathrm{Hj}$ of the difluorocyclopropene 3a-c and alkyne 2a-c. ${ }^{\mathrm{b}}$ Following column chromatography in larger scale syntheses.

Encouraged by the observed conversion in the NMR scale experiments, large scale syntheses were carried out in a pressure tube and difluorocyclopropenes 3a-c were isolated in moderate to good yields following column chromatography (Table 1, SI Section 2). In addition, the X-ray crystal structure of $\mathbf{3 a}$ was obtained showing the expected difluorocyclopropene structure (SI Section 2.1.2.1, Figure $\mathrm{S} 12) .{ }^{\ddagger}$ The $\mathrm{C}=\mathrm{C}$ bond length $(1.33 \AA)$ and $\mathrm{C}-\mathrm{F}$ bond lengths $(1.38 \AA)$ in the cyclopropene ring are similar to those in related difluorocyclopropenes. ${ }^{86,87}$

Although synthetic access to the desired difluorocyclopropenes was initially envisaged to be challenging, the cycloaddition strategy was tolerant of both the 2,2'-bipyridine coordination motif and a second heterocyclic 6-quinoline substituent. Furthermore, the difluorocyclopropene derivatives were stable during purification by column chromatography on silica gel. This was surprising since other difluorocyclopropenes and related difluorocyclopropanes are susceptible to hydrolysis under relatively mild conditions, ${ }^{38,56,74}$ including on silica gel, ${ }^{56,81,86,88}$ giving the corresponding cyclopropenones and cyclopropanones, respectively. 
Indeed, attempted hydrolysis of $\mathbf{3 a - c}$ to cyclopropenones 1a-c on a small scale under a variety of mild conditions (wet $\mathrm{CDCl}_{3}, \mathrm{Amberlyst}^{\circledR} 15$ or silica gel at room temperature for $24 \mathrm{~h})^{38,56,74,80}$ revealed the stability of the difluorocyclopropenes (SI, Section 4); while there was no hydrolysis of $3 c$ under these conditions (Figure S58, A-C), derivatives $\mathbf{3} \mathbf{a}-\mathbf{b}$ showed partial hydrolysis using Amberlyst ${ }^{\circledR} 15$ and silica gel (Figures S56-S57, B-C) and no hydrolysis in $\mathrm{CDCl}_{3}$ (Figures S56-S57, A). In contrast, complete hydrolysis was observed using $6 \mathrm{M} \mathrm{HCl}$ since the cyclopropenone was obtained following neutralisation and extraction with $\mathrm{CDCl}_{3}$ (Figures S56-S57, D). Despite the complete consumption of quinoline derivative $\mathbf{3 c}$, it was necessary to shorten the reaction time to $1 \mathrm{~h}$ to prevent the formation of a by-product (Figure S58, D-D.1).

Further optimisation of this hydrolysis method with $\mathrm{HCl}$ enabled the preparative isolation of $\mathrm{N}$-heterocyclic cyclopropenones in good yields (65-91\%) with a reaction time of $15 \mathrm{~min}$ for $\mathbf{1 a}$ and $\mathbf{1 b}$ and $1 \mathrm{~h}$ for derivative $\mathbf{1 c}$. Evidence for the formation of 1a-c was given by the distinct shift of the carbonyl carbon ${ }^{39,50,89}$ around 150-156 ppm in the ${ }^{13} \mathrm{C}$ NMR spectra (Figures S14, S30 and S46), observation of the molecular ion peak in the ESI mass spectra as well as the characteristic carbonyl stretches and ring vibrations $25,28,39,90$ in the ranges of $1835-1850 \mathrm{~cm}^{-1}$ and $1560-1625 \mathrm{~cm}^{-1}$ in the IR spectra (SI Sections 2.1.3, 2.2.3, 2.3.3).

With the successful synthesis of the series of 2,2'-bipyridine-based ligands 1a-c, the stability of this new class of cyclopropenones was investigated regarding storage and handling. No decomposition of solid samples was observed over at least a month at room temperature under ambient light. However, solutions of the cyclopropenones in $\mathrm{CDCl}_{3}$ under ambient light showed evidence of decarbonylation over a period of one week (SI Section 5, Figures S62-64) As a result, all cyclopropenones in solution were protected from light as a precaution.

Irradiation studies were carried out using UV/vis and NMR spectroscopy to investigate the influence of the $R$ substituent on photodecarbonylation (Scheme 3, SI Section 6). Since the synthesis and study of the M-CPOnes was carried out in acetonitrile, the UV/vis spectra of ligands $\mathbf{1 a - c}$ as well as reference alkyne derivatives $\mathbf{2 a - c}$ were measured in acetonitrile. However, due to the limited solubility of the ligands at typical NMR concentrations in acetonitrile, the NMR studies with the ligands were performed in $\mathrm{CDCl}_{3}$.

The UV/vis spectra of cyclopropenones 1a-c show broad absorption bands and as expected based on studies of related cyclopropenones with alkyl and aryl substituents, ${ }^{50}$ the $R$ substituent tunes the absorption maximum from $321 \mathrm{~nm}$ (1a) to $333 \mathrm{~nm}$ (1c) and $341 \mathrm{~nm}$ (1b) (Figure 1a). Photodecarbonylation of related cyclopropenones has been reported upon irradiation of the absorption bands around $240-325 \mathrm{~nm}$ and $360 \mathrm{~nm}$

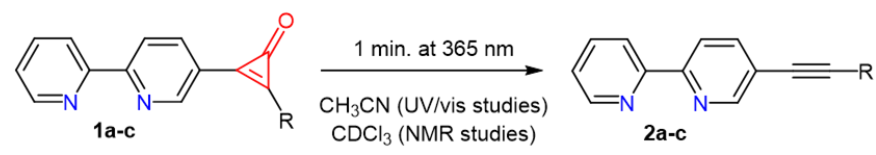

Scheme 3. Photodecarbonylation of cyclopropenone ligands 1a-c to $2 \mathrm{a}-\mathrm{c}$.

assigned to the $\pi-\pi^{*}$ and $n-\pi^{*}$ transitions, respectively. ${ }^{50}$, 91-95 Irradiation of the $\pi-\pi^{*}$ absorption band is proposed to produce the corresponding alkyne in the excited state in contrast to the ground state following irradiation of the $n-\pi^{*}$ absorption band. ${ }^{94}$ A wavelength of $365 \mathrm{~nm}$ was chosen to trigger the photodissociation in these studies for this reason and since the absorbance of the alkynes are minimal at this wavelength; in related systems, the alkyne photoproducts are reported to undergo subsequent photoreactions. ${ }^{50}$

Irradiation for $1 \mathrm{~min}$ with all cyclopropenones showed complete photodecarbonylation to the corresponding alkyne derivatives (Figure $1 \mathrm{~b}$ ). The ${ }^{1} \mathrm{H}$ and ${ }^{13} \mathrm{C}$ NMR spectra as well as the UV/vis spectra were consistent with the reference alkyne spectra (Figures S65-S73). Furthermore, no by-products were observed in the NMR spectra.
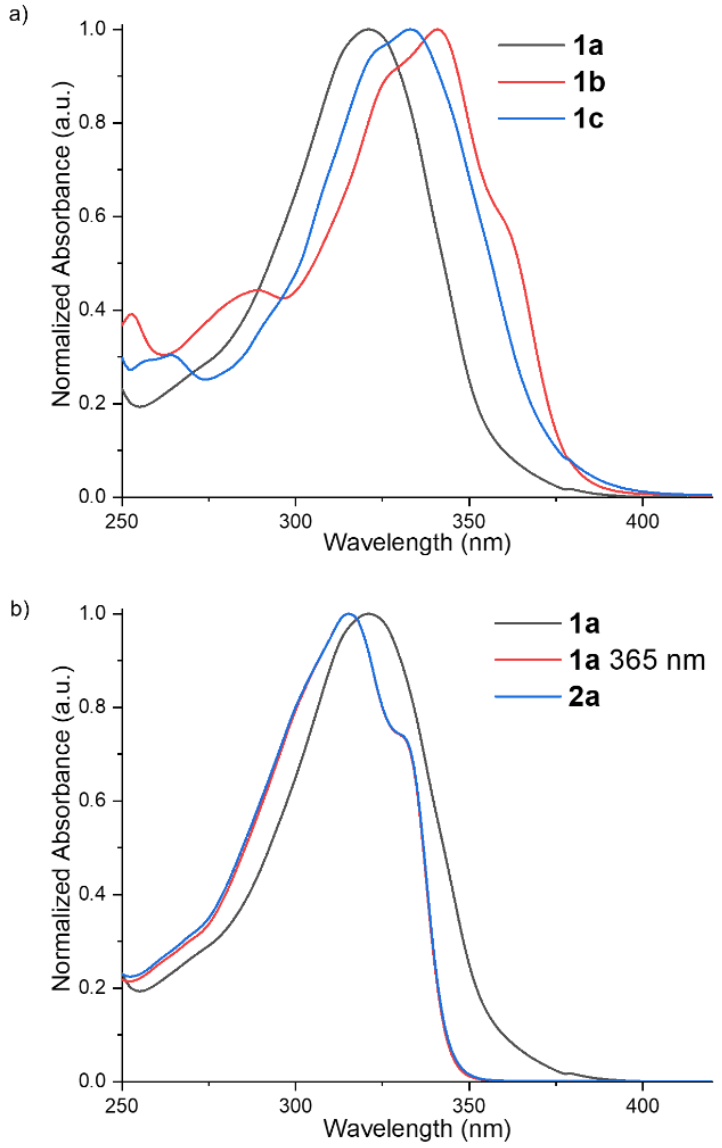

Figure 1. Comparison of the normalized UV/vis spectra $\left(\mathrm{CH}_{3} \mathrm{CN}\right.$, 298 K) of: a) cyclopropenone ligands $\mathbf{1 a - c}$; b) cyclopropenone ligand 1a before (black) and after (red) irradiation with $365 \mathrm{~nm}$ for $1 \mathrm{~min}$ as well as the reference compound $\mathbf{2 a}$ (blue). 
As the desired cyclopropenone ligands 1a-c were obtained, their complexation with $\mathrm{Fe}\left(\mathrm{BF}_{4}\right)_{2} \cdot 6 \mathrm{H}_{2} \mathrm{O}, \mathrm{Zn}(\mathrm{OTf})_{2}$ and $\mathrm{Co}\left(\mathrm{NTf}_{2}\right)_{2}$ was investigated in proof-of-concept studies to establish the compatibility of the cyclopropenone moiety with transition metal complexes regarding stability and photodecarbonylation. The M-CPOnes were prepared by mixing the respective metal salt and three equivalents of the ligand in $\mathrm{CD}_{3} \mathrm{CN}$ and were characterised by $\mathrm{NMR}$, UV/Vis, IR spectroscopy and ESI spectrometry either in situ or after precipitation with diethyl ether. Since these non-symmetric ligands could form a mixture of meridional (mer) and facial ( $f a c$ ) coordination isomers, up to four sets of NMR signals were to be expected.

In addition, the corresponding alkyne complexes M-2a-c (M = Fe"l, $\mathrm{Zn}^{\prime \prime}$ and $\left.\mathrm{Co}^{\prime \prime}\right)$ were synthesised for comparison since they are formed upon photodecarbonylation of the M-CPOnes (Scheme 1). Although the nitrogen donor of the quinoline substituent in ligand $\mathbf{2 c}$ could, in principle, also coordinate to the metal leading to ill-defined complex mixtures, the NMR spectra for complexes $\mathrm{Fe}-\mathbf{2 c}$ and $\mathrm{Co}-2 \mathrm{c}$ were consistent with metal binding to the 2,2'-bipyridine motif only when a $1: 3$ metal/ligand ratio was used (Figures S162-166, S168173).

Complexation of cyclopropenone ligands $\mathbf{1 a}$ and $\mathbf{1 b}$ with $\mathrm{Zn}$ " and $\mathrm{Fe}^{\text {Il }}$ resulted in the formation of diamagnetic complexes (Figures S74-S75, S80-S81, S95-S96, S101S102) with different ${ }^{1} \mathrm{H}$ and ${ }^{13} \mathrm{C}$ NMR spectra to the alkyne complexes Zn-2a,b and Fe-2a,b (Figures S125-S126, S131-S132, S145-S146, S151-152). However, complete assignment of the spectra was not possible for the Zn-CPOnes-1a,b due to broad linewidths and overlapping signals, although ESI mass spectra were consistent with the formation of $\mathrm{ZnL}_{3}$ complexes (Figures S84, S106). Characterisation of Fe-CPOnes-1a,b was also challenging given the number of overlapping signals, however, the signals for $\mathrm{H}_{\mathrm{j}}$ were distinct and four sets were observed (Figures S74 and S95). This along with the observation of four sets of signals for each carbon in the ${ }^{13} \mathrm{C}$ NMR spectra suggests the formation of a mixture of fac and mer isomers (Figures S75 and S96). In contrast to the challenging NMR analysis with the $\mathrm{Zn}^{\prime \prime}$ and $\mathrm{Fe}^{\prime \prime}$ complexes due to signal overlap, the formation of paramagnetic complexes with Co"l resulted in greater signal dispersion due to the large paramagnetic shifts. Characterisation using our recently developed paramagnetic NMR toolbox ${ }^{96}$ revealed four ligand environments consistent with a mixture of the fac and mer isomers (Figures S87-S93, S107-S112).

Evidence for the cyclopropenone moiety being intact following complexation comes from observation of the carbonyl carbon signals in the ${ }^{13} \mathrm{C}$ NMR spectra of the diamagnetic $\mathrm{Fe}^{\text {ll }}$ complexes at similar shifts to the free ligands as well as the distinctive carbonyl stretches and ring vibrations in the IR spectra of M-CPOne-1a,b $\left(M=F e^{I I}\right.$, $\left.Z n^{\prime \prime}, C^{\prime \prime}\right)$. Furthermore, ESI mass spectra confirmed the formation of M-CPOne-1a,b (M = Fe", $\left.\mathrm{Zn}^{\prime \prime}, \mathrm{Co}^{\prime \prime}\right)$ through the observation of the $\left[\mathrm{ML}_{3}\right]^{2+}$ ion peaks as well as $\left[\mathrm{ML}_{3}-(\mathrm{CO})_{n}\right]^{2+} \quad(\mathrm{n}=1-3)$ ion peaks resulting from decarbonylation under the ionisation conditions (Figures S79, S84, S94, S100, S106, S113).
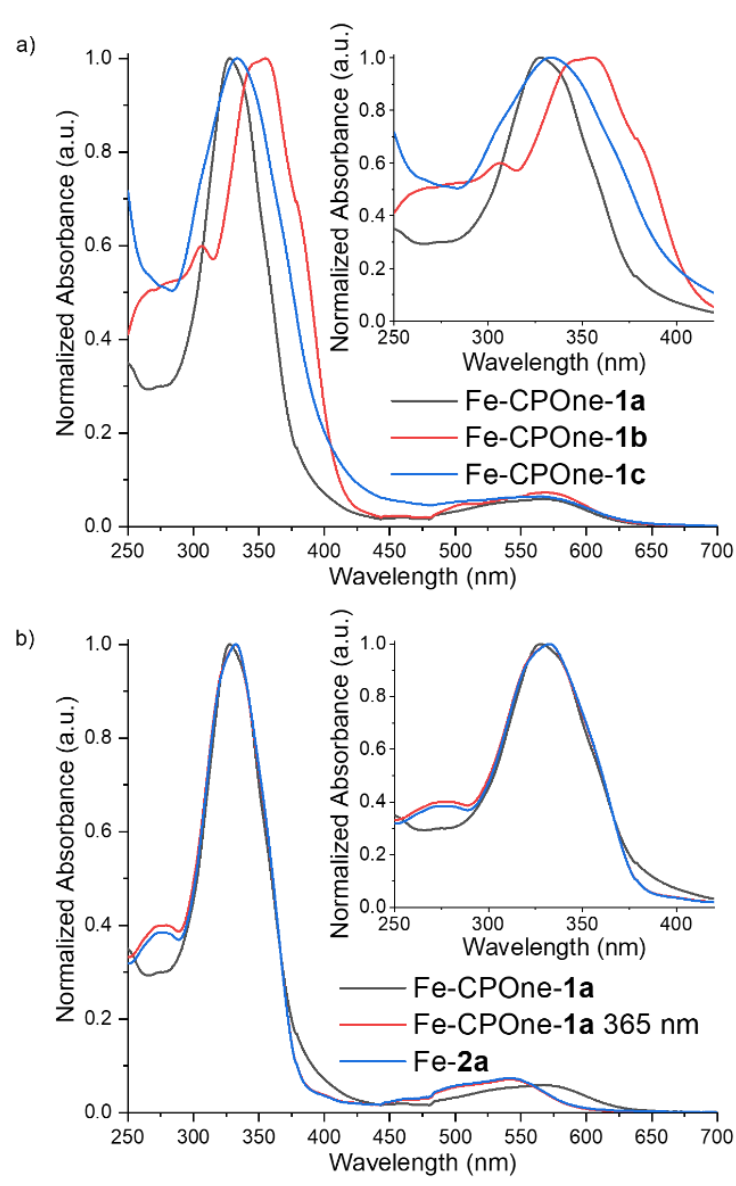

Figure 2. Comparison of the normalized UV/vis spectra $\left(\mathrm{CH}_{3} \mathrm{CN}\right.$, 298 K) of: a) Fe-CPOnes-1a-c; b) Fe-CPOne-1a before (black) and after (red) irradiation with $365 \mathrm{~nm}$ for $1 \mathrm{~min}$ as well as the reference complex Fe-2a (blue). The insets show an expansion of the spectra between 250 and $400 \mathrm{~nm}$ for comparison of the absorption maxima.

The photophysical properties of the cyclopropenone in M-CPOne-1a,b (M = Fe", $\left.\mathrm{Zn}^{\prime \prime}, \mathrm{Co}^{\prime \prime}\right)$ were similar to those of the free cyclopropenone ligand $\mathbf{1 a}$ and $\mathbf{1 b}$ with small bathochromic shifts of the absorption maxima in the UV/vis spectra in acetonitrile (Figures S176, S179, S181, S184, $S 189, S 191)$. As with the free ligands, the $R$ substituent tunes the absorption maximum with a $30 \mathrm{~nm}$ difference between Fe-CPOne-1a and Fe-CPOne-1b (Figure 2a, inset).

Irradiation experiments were carried out by UV/vis and NMR spectroscopy using $365 \mathrm{~nm}$ light given the similarity of the absorption maxima to those of the free ligands (Scheme 1, Figures $1 \mathrm{a}$ and $2 \mathrm{a}$ ). Following irradiation of M-CPOne-1a,b (M = Fe"l, Zn", Co") for $1 \mathrm{~min}$, UV/vis spectra consistent with the corresponding alkyne complexes $\mathbf{M - 2 a , b}$ were obtained, suggesting complete photodecarbonylation of M-CPOne-1a,b (SI Section 9). Further studies using NMR spectroscopy supported photodecarbonylation to the corresponding alkyne complexes M-2a,b. However, longer irradiation times of $4 \mathrm{~min}$ and $20 \mathrm{~min}$ were required for photodecarbonylation of Co-CPOne-1a,b and Fe-CPOne-1a,b, respectively, attributed to the increased concentration for the NMR studies ( $\mathrm{mM}$ vs $\mu \mathrm{M}$ for NMR and UV/vis studies, 
respectively) and competing absorbance of the alkyne complexes at $365 \mathrm{~nm}$.

In addition to these photodecarbonylation properties, the M-CPOnes have tunable properties due to the presence of the metal. The fluorescent properties of $\mathrm{Zn-CPOne-1a}$ and its corresponding alkyne complex $\mathrm{Zn}-2 \mathrm{a}$ were also investigated. Upon excitation at $312 \mathrm{~nm}$ $\mathrm{Zn}-2 \mathrm{a}$ showed emission at $362 \mathrm{~nm}$ and a similar emission spectrum was obtained for Zn-CPOne-1a, although the fluorescence was weaker (Figures S85, S86, S177). Similar spectra were obtained for the corresponding ligands $\mathbf{1 a}$ and $\mathbf{2 a}$ (Figures S85, S86). We propose that $\mathrm{Zn}$-CPOne-1a shows no/weak fluorescence and some photodecarbonylation takes places at this excitation wavelength, as observed by Popik and co-workers for related cyclopropenones. ${ }^{50}$ Thus, the fluorescence from the photodecarbonylated products of $\mathrm{Zn}$-CPOnes could be exploited as another indicator of $\mathrm{CO}$ release. For Fe-CPOne-1a,b CO release could be followed through the hypsochromic shift of the MLCT band around $570 \mathrm{~nm}$ upon irradiation (Figures 2b, S181, S184), resulting in a colour change from purple to red (Figure S182). Finally, photodecarbonylation of Co-CPOne-1a,b resulted in shifts of up to $5 \mathrm{ppm}$ for the bipyridine coordination motif signals in the paramagnetic NMR spectrum (Figures S188, S190).

Over the course of our studies, we found the quinoline-containing ligand 1c showed different coordination properties to the corresponding alkyne ligand $\mathbf{2 c}$ and cyclopropenone ligands $\mathbf{1 a - 1} \mathbf{b}$. Given the characterisation difficulty with Zn-CPOnes due to the broadness of the NMR spectra, we focussed on the preparation of $\mathrm{M}$-CPOnes-1c $\left(\mathrm{M}=\mathrm{Fe}^{\|}\right.$, $\left.\mathrm{Co}^{\prime \prime}\right)$ using the same procedure as previously described. While ${ }^{1} \mathrm{H}$ NMR and mass spectra consistent with the formation of Fe-CPOne-1c and Co-CPOne-1c were observed immediately after preparation (Figures S114, S116-S119, S121-124), the signals in the NMR spectra decreased in intensity over time (Figures S115, S120). There was also a colour change as well as partial precipitation. We propose the observed spectral changes for Fe-CPOne-1c and Co-CPOne-1c are due to the rearrangement of kinetically formed metastable M-CPOnes-1c $\left(\mathrm{M}=\mathrm{Fe}^{\|}\right.$, Co") to a dynamic combinatorial library of multiple interconverting species. This is attributed to the presence of an additional coordination motif, the 6-quinoline, and its orientation in the bent cyclopropenone ligand given complexes $\mathrm{M}-2 \mathrm{c}$ did not rearrange.

Indeed, irradiation experiments with the proposed dynamic combinatorial library samples as well as freshly prepared M-CPOnes-1c ( $\mathrm{M}=\mathrm{Fe}^{\prime \prime}$, Co"l) using NMR spectroscopy showed similar NMR spectra to the respective alkyne complexes $\mathrm{M}-\mathbf{1 c}$ following irradiation at $365 \mathrm{~nm}$ for $4 \mathrm{~min}\left(\mathrm{M}=\mathrm{Co}^{\prime \prime}\right)$ or $20 \operatorname{mins}\left(\mathrm{M}=\mathrm{Fe}^{\prime \prime}\right)$. In addition, the freshly prepared M-CPOne-1c complexes showed spectral changes consistent with photodecarbonylation (Figures S185, S186, S192, S193). This suggests that the change of the NMR spectra over time was not due to decomposition of the cyclopropenone motif but due to additional coordination events since photodecarbonylation was still possible following rearrangement to the proposed dynamic combinatorial library.

\section{Conclusions}

A family of M-CPOnes was successfully prepared as a new class of CO-releasing molecules combining the lighttriggered decarbonylation of cyclopropenones with the tunability of transition metal complexes. Firstly, we demonstrated $N$-heterocyclic cyclopropenones based on electron-deficient 2,2'-bipyridine coordination motifs are synthetically accessible via a cycloaddition and subsequent hydrolysis of the difluorocyclopropenes. Furthermore, the ligands are stable to coordination with $\mathrm{Zn}^{\prime \prime}, \mathrm{Fe}^{\mathrm{Il}}$ and Co" forming the M-CPOnes. Special handling and storage of the ligands and their corresponding M-CPOnes was not necessary, other than exclusion of ambient light for samples in solution. Upon irradiation with a suitable wavelength, photodecarbonylation of M-CPOne to the corresponding alkyne complex was observed, thus demonstrating the proof-of-concept.

The advantage of M-CPOnes is their modularity since up to 3 CO-releasing ligands can be incorporated within one complex and their properties can be readily tuned via the metal ion as well as the cyclopropenone substituents. For example, the absorbance maximum of the cyclopropenones in the M-CPOnes and their corresponding ligands was modulated by the $R$ substituent with a bathochromic shift of up to almost $30 \mathrm{~nm}$ for the thienyl relative to the phenyl substituent.

The presence of the metal ion confers additional properties so that the photodecarbonylation of the $\mathrm{Zn}$-CPOnes could be detected by fluorescence, the Fe-CPOnes by the shift of the MLCT band and the Co-CPOnes by paramagnetic NMR spectroscopy due to the greater dispersion of the signals, particularly for the bipyridine coordination motif given its proximity to the Co" centre. The ability to track photodecarbonylation by a variety of spectroscopic methods dependent on the metal ion will be beneficial for future applications of M-CPOnes.

Furthermore, M-CPOnes are compatible with incorporation of a second coordination site, 6-quinoline, and the initially formed M-CPOnes-1c $\left(\mathrm{M}=\mathrm{Co}^{\|}\right.$, Fe" $)$were proposed to rearrange into dynamic combinatorial libraries that still undergo photodecarbonylation to the corresponding M-2c complexes. This opens up avenues for supramolecular M-CPOnes and will be the subject of future investigations as well as broadening the scope of the metals within M-CPOnes.

\section{Conflicts of interest}

There are no conflicts to declare.

\section{Acknowledgements}

We thank the Deutsche Forschungsgemeinschaft (DFG, project number 413396832) for financial support. We thank 
the spectroscopy department, Dr Claus Bier and Johanna Baum for NMR and mass spectral data collection. We also thank Marvin Grünhagen for preliminary studies.

\section{Notes and References}

₹ CCDC 2142653 contains the supplementary crystallographic data for this paper. These data can be obtained free of charge from the Cambridge Crystallographic Data Centre via http://www.ccdc.cam.ac.uk/data_request/cif.

1. S. H. Heinemann, T. Hoshi, M. Westerhausen and A. Schiller, Chem. Commun., 2014, 50, 3644-3660.

2. L. Y. Wu and R. Wang, Pharmacol. Rev., 2005, 57, 585-630.

3. R. Motterlini, B. E. Mann and R. Foresti, Expert Opin. Invest. Drugs, 2005, 14, 1305-1318.

4. R. Motterlini and L. E. Otterbein, Nat. Rev. Drug Discovery, 2010, 9, 728-743.

5. C. P. Hopper, L. Meinel, C. Steiger and L. E. Otterbein, Curr. Pharm. Des., 2018, 24, 2264-2282.

6. A. Walewska, A. Szewczyk and P. Koprowski, Int. J. Mol. Sci., $2018,19,3227$.

7. H. Bae, T. Kim and I. Lim, Korean J. Physiol. Pharmacol., 2021, 25, 227-237.

8. A. Verma, D. J. Hirsch, C. E. Glatt, G. V. Ronnett and S. H. Snyder, Science, 1993, 259, 381-384

9. D. Stucki, J. Steinhausen, P. Westhoff, H. Krahl, D. Brilhaus, A Massenberg, A. P. M. Weber, A. S. Reichert, P. Brenneisen and W. Stahl, Antioxidants, 2020, 9, 251-260.

10. B. E. Mann, Organometallics, 2012, 31, 5728-5735.

11. R. Motterlini, J. E. Clark, R. Foresti, P. Sarathchandra, B. E. Mann and C. J. Green, Circ. Res., 2002, 90, E17-E24.

12. R. Foresti, J. Hammad, J. E. Clark, T. R. Johnson, B. E. Mann, A. Friebe, C. J. Green and R. Motterlini, Brit. J. Pharmacol., 2004, 142, 453-460.

13. N. Abeyrathna, K. Washington, C. Bashur and Y. Liao, Org. Biomol. Chem., 2017, 15, 8692-8699.

14. X. Y. Ji and B. H. Wang, Acc. Chem. Res., 2018, 51, 13771385.

15. J. T. B. Kueh, N. J. Stanley, R. J. Hewitt, L. M. Woods, L. Larsen, J. C. Harrison, D. Rennison, M. A. Brimble, I. A Sammut and D. S. Larsen, Chem. Sci., 2017, 8, 5454-5459.

16. T. Slanina and P. Sebej, Photochem. Photobiol. Sci., 2018, 17, 692-710.

17. U. Schatzschneider, Inorg. Chim. Acta, 2011, 374, 19-23.

18. L. S. Lazarus, A. D. Benninghoff and L. M. Berreau, Acc. Chem. Res., 2020, 53, 2273-2285.

19. J. Cheng, G. H. Gan, Z. Q. Shen, L. Gao, G. Y. Zhang and J. M. Hu, Angew. Chem., Int. Ed., 2021, 60, 13513-13520.

20. R. N. Pickens, G. L. Judd and J. K. White, Chem. Commun. 2021, 57, 7713-7716.

21. W. Feng, S. Feng and G. Feng, Chem. Commun., 2019, 55, 8987-8990.

22. P. Peng, C. M. Wang, Z. Shi, V. K. Johns, L. Y. Ma, J. Oyer, A Copik, R. Igarashi and Y. Liao, Org. Biomol. Chem., 2013, 11, 6671-6674.

23. L. K. C. De La Cruz, S. L. Benoit, Z. X. Pan, B. C. Yu, R. J. Maier, X. Y. Ji and B. H. Wang, Org. Lett., 2018, 20, 897-900.

24. Y. Q. Zheng, X. Y. Ji, B. C. Yu, K. L. Ji, D. Gallo, E. Csizmadia M. Y. Zhu, M. R. Choudhury, L. K. C. De La Cruz, V. Chittavong, Z. X. Pan, Z. N. Yuan, L. E. Otterbein and B. H. Wang, Nat Chem., 2018, 10, 787-794.

25. K. T. Potts and J. S. Baum, Chem. Rev., 1974, 74, 189-213.

26. K. Komatsu and T. Kitagawa, Chem. Rev., 2003, 103, 1371. 1428.

27. N. K. Urdabayev, A. Poloukhtine and V. V. Popik, Chem. Commun., 2006, 454-456.

28. A. Poloukhtine and V. V. Popik, J. Phys. Chem. A, 2006, 110 $1749-1757$.

29. X. Li, C. Han, H. Yao and A. Lin, Org. Lett., 2017, 19, 778-781.

30. T. Matsuda, K. Yamanaka, Y. Tabata and T. Shiomi, Tetrahedron Lett., 2018, 59, 1458-1460.

31. T. Matsuda, Y. Tabata and H. Suzuki, New J. Chem., 2018, 42, 19178-19182.

32. H. M. Xing, J. Chen, Y. S. Shi, T. L. Huang, L. Hai and Y. Wu Org. Chem. Front., 2020, 7, 672-677.
33. Y. S. Shi, H. M. Xing, T. L. Huang, X. X. Liu, J. Chen, X. Y. Guo, G. B. Li and Y. Wu, Chem. Commun., 2020, 56, 1585-1588.

34. J. L. Xu, H. Tian, J. H. Kang, W. X. Kang, W. Sun, R. Sun, Y. M. Li and M. Sun, Org. Lett., 2020, 22, 6739-6743.

35. S. W. Liu, C. Yuan, X. F. Jiang, X. X. Wang and H. L. Cui, Asian J. Org. Chem., 2020, 9, 82-85.

36. J. Wu, W. X. Gao, X. B. Huang, Y. B. Zhou, M. C. Liu and H. Y. Wu, Org. Lett., 2020, 22, 5555-5560.

37. Y. L. Yang, Z. Zhang, X. N. Zhang, D. Wang, Y. Wei and M. Shi, Chem. Commun., 2014, 50, 115-117.

38. A. V. Kuzmin and V. V. Popik, Chem. Commun., 2009, 57075709 .

39. C. M. Vanos and T. H. Lambert, Angew. Chem., Int. Ed., 2011 50, $12222-12226$

40. E. D. Nacsa and T. H. Lambert, Org. Lett., 2013, 15, 38-41.

41. C. C. Shao, H. Y. Duan, Y. Q. Min and X. H. Zhang, Chin. Chem. Lett., 2020, 31, 299-302.

42. M. Denis, D. Gindre and F. X. Felpin, J. Mater. Sci., 2021, 56, 5006-5014.

43. D. A. Sutton and V. V. Popik, J. Org. Chem., 2016, 81, 88508857.

44. D. A. Sutton, S. H. Yu, R. Steet and V. V. Popik, Chem. Commun., 2016, 52, 553-556.

45. R. D. Row, H. W. Shih, A. T. Alexander, R. A. Mehl and J. A Prescher, J. Am. Chem. Soc., 2017, 139, 7370-7375.

46. W. Luo, P. Gobbo, C. D. McNitt, D. A. Sutton, V. V. Popik and M. S. Workentin, Chem. - Eur. J., 2017, 23, 1052-1059.

47. R. D. Row, S. S. Nguyen, A. J. Ferreira and J. A. Prescher, Chem. Commun., 2020, 56, 10883-10886.

48. L. Y. Sun, Y. K. Gai, C. D. McNitt, J. Sun, X. H. Zhang, W. Xing, Z. H. Li, V. V. Popik and D. X. Zeng, J. Org. Chem., 2020, 85, 5771-5777.

49. J. L. Benham, R. West and J. A. T. Norman, J. Am. Chem. Soc. 1980, 102, 5047-5053.

50. A. P. Vladimir and V. V. Popik, J. Org. Chem., 2003, 68, 78337840.

51. R. Chotima, T. Dale, M. Green, T. W. Hey, C. L. McMullin, A. Nunns, A. G. Orpen, I. V. Shishkov, D. F. Wass and R. L. Wingad, Dalton Trans., 2011, 40, 5316-5323.

52. E. I. Klimova, E. A. V. Lopez, M. F. Alamo, L. A. Ortiz-Frade, G. Hernandez-Sanchez, V. H. S. Dominguez and M. M. Garcia, J. Heterocycl. Chem., 2012, 49, 1156-1162.

53. J. J. S. Garcia, R. S. Joo-Cisneros, D. Garcia-Bassoco, M. Flores-Alamo, J. M. M. Stivalet, J. Garcia-Valdes and E. I. Klimova, J. Organomet. Chem., 2021, 944, 121809.

54. K. A. Netland, L. L. Gundersen and F. Rise, Synth. Commun., $2000,30,1767-1777$.

55. O. Korner, R. Gleiter and F. Rominger, Synthesis, 2009, 32593262.

56. P. Rulliere, P. Cyr and A. B. Charette, Org. Lett., 2016, 18 1988-1991.

57. T. Nanda, P. Biswal, B. V. Pati, S. K. Banjare and P. C. Ravikumar, J. Org. Chem., 2021, 86, 2682-2695.

58. R. Breslow, L. J. Altman, A. Krebs, E. Mohacsi, I. Murata, R. A Peterson and J. Posner, J. Am. Chem. Soc., 1965, 87, 1326-\&. K. Matsumoto, A. Okada, T. Girek, Y. Ikemi, J. C. Kim, N. Hayashi, H. Yoshida and A. Kakehi, Heterocycl. Commun., 2002, 8, 325-328.

60. M. Isaka, R. Ando, Y. Morinaka and E. Nakamura, Tetrahedron Lett., 1991, 32, 1339-1342.

61. M. Isaka, S. Ejiri and E. Nakamura, Tetrahedron, 1992, 48 2045-2057.

62. M. Nakamura, H. Isobe and E. Nakamura, Chem. Rev., 2003 , 103, 1295-1326.

63. M. Cohen, U. Bretler and A. Albeck, Protein Science, 2013, 22 , 788-799.

64. A. A. Poloukhtine, N. E. Mbua, M. A. Wolfert, G. J. Boons and V. V. Popik, J. Am. Chem. Soc., 2009, 131, 15769-15776.

65. N. K. Urdabayev, A. Poloukhtine and V. V. Popik, Chem. Commun., 2006, 454-456.

66. C. D. McNitt, H. Cheng, S. Ullrich, V. V. Popik and M. Bjerknes, J. Am. Chem Soc., 2017, 139, 14029-14032.

67. M. G. Wilkerson, J. Henkin and J. K. Wilkin, J. Am. Acad Dermatol., 1984, 11, 802-807.

68. T. Wasylyszyn and K. Borowska, Acta. Pol. Pharm., 2016, 73 1455-1460.

69. K. Borowska and T. Wasylyszyn, Acta. Pol. Pharm., 2017, 74, 459-464. 

M. Corsini, P. Zanello, S. Hernandez-Ortega and M. M. Garcia, Eur. J. Org. Chem., 2003, 2003, 4265-4272.

71. T. Klimova, E. I. Klimova, M. M. Garcia, C. A. Toledano and R. A. Toscano, J. Organomet. Chem., 2003, 665, 23-28.

72. Z. M. Strater, M. Rauch, S. Jockusch and T. H. Lambert, Angew. Chem., Int. Ed., 2019, 58, 8049-8052.

73. G. Ernouf, J. L. Brayer, B. Folleas, J. P. Demoute, C. Meyer and J. Cossy, J. Org. Chem., 2017, 82, 3965-3975.

74. S. S. Nguyen, A. J. Ferreira, Z. G. Long, T. K. Heiss, R. S. Dorn, R. D. Row and J. A. Prescher, Org. Lett., 2019, 21, 8695-8699.

75. Y. V. Skornyakov, N. A. Lozinskaya, M. V. Proskurnina and N. S. Zefirov, Russ. J. Org. Chem., 2005, 41, 689-693.

76. R. Sunke, S. B. Nallapati, J. S. Kumar, K. S. Kumar and M. Pal, Org. Biomol. Chem., 2017, 15, 4042-4057.

77. D. L. S. Brahms and W. P. Dailey, Chem. Rev., 1996, 96, 15851632.

78. W. R. Dolbier and M. A. Battiste, Chem. Rev., 2003, 103, 10711098.

79. F. Wang, W. Zhang, J. M. Zhu, H. F. Li, K. W. Huang and J. B. $\mathrm{Hu}$, Chem. Commun., 2011, 47, 2411-2413.

80. L. C. Li, F. Wang, C. F. Ni and J. B. Hu, Angew. Chem., Int. Ed., 2013, 52, 12390-12394.

81. F. Wang, T. Luo, J. B. Hu, Y. Wang, H. S. Krishnan, P. V. Jog, S. K. Ganesh, G. K. S. Prakash and G. A. Olah, Angew. Chem., Int. Ed., 2011, 50, 7153-7157.

82. C. F. Ni and J. B. Hu, Synthesis, 2014, 46, 842-863.

83. G. Tran, D. G. Pardo, T. Tsuchiya, S. Hillebrand, J. P. Vors and J. Cossy, Org. Lett., 2015, 17, 3414-3417.

84. R. Eujen and B. Hoge, J. Organomet. Chem., 1995, 503, C51C54.

85. X. Y. Deng, J. H. Lin, J. Zheng and J. C. Xiao, Chem. Commun., 2015, 51, 8805-8808.

86. A. K. Brisdon, I. R. Crossley, K. R. Flower, R. G. Pritchard and J. E. Warren, Angew. Chem., Int. Ed., 2003, 42, 2399-2401.

87. Z. L. Cheng and Q. Y. Chen, Synlett, 2006, 478-480.

88. T. Nihei, T. Hoshino and T. Konno, Org. Lett., 2014, 16, 41704173.

89. G. Kuzmanich, M. N. Gard and M. A. Garcia-Garibay, J. Am. Chem. Soc., 2009, 131, 11606-11614

90. S. Staicu, I. G. Dinulescu, F. Chiraleu and M. Avram, J. Organomet. Chem., 1976, 113, C69-C72.

91. G. Quinkert, K. Opitz, W. W. Wiersdorff and J. Weinlich, Tetrahedron Lett., 1963, 27, 1863-1868.

92. Y. Hirata and N. Mataga, Chem. Phys. Lett., 1992, 193, 287291.

93. R. W. Fessenden, P. M. Carton, H. Shimamori and J. C. Scalano, J. Phys. Chem., 1982, 86, 3803-3811.

94. Y. Hirata, T. Okada, N. Mataga and T. Nomoto, J. Phys. Chem., 1992, 96, 6559-6563.

95. S. Takeuchi and T. Tahara, J. Chem. Phys., 2004, 120, 47684776.

96. M. Lehr, T. Paschelke, E. Trumpf, A. M. Vogt, C. Näther, F. D. Sönnichsen and A. J. McConnell, Angew. Chem., Int. Ed., 2020, 59, 19344-19351. 